\title{
inaw \\ Complementary Nutrients in Decoupled Aquaponics Enhance Basil Performance
}

\author{
Dylan Rodgers ${ }^{1, *(1)}$, Eugene Won ${ }^{2}$, Michael B. Timmons ${ }^{3}{ }^{(1)}$ and Neil Mattson ${ }^{4, *}$ \\ 1 Department of Natural Resources, Cornell University, Ithaca, NY 14853, USA \\ 2 Department of Animal Science, Cornell University, Ithaca, NY 14853, USA; etw36@cornell.edu \\ 3 Department of Biological and Environmental Engineering, Cornell University, Ithaca, NY 14853, USA; \\ mbt3@cornell.edu \\ 4 School of Integrative Plant Science, Horticulture Section, Cornell University, Ithaca, NY 14853, USA \\ * Correspondence: dpr77@cornell.edu (D.R.); neil.mattson@cornell.edu (N.M.); Tel.: +1-303-907-9059 (D.R.)
}

check for updates

Citation: Rodgers, D.; Won, E.; Timmons, M.B.; Mattson, N. Complementary Nutrients in Decoupled Aquaponics Enhance Basil Performance. Horticulturae 2022, 8, 111. https://doi.org/10.3390/ horticulturae 802011

Academic Editor: Luigi De Bellis

Received: 14 December 2021

Accepted: 21 January 2022

Published: 26 January 2022

Publisher's Note: MDPI stays neutral with regard to jurisdictional claims in published maps and institutional affiliations.

Copyright: (C) 2022 by the authors. Licensee MDPI, Basel, Switzerland. This article is an open access article distributed under the terms and conditions of the Creative Commons Attribution (CC BY) license (https:// creativecommons.org/licenses/by/ $4.0 /)$.

\begin{abstract}
Aquaponics combines raising fish and growing plants by recycling water and nutrients to reduce water consumption and reliance on chemical fertilizers. Coupled aquaponics systems recirculate water between fish and plant crops, whereas decoupled systems send mineralized fish effluent and wastewater unidirectionally to an independent hydroponic loop. Decoupling enables changes to the water, such as $\mathrm{pH}$ adjustments and complementary nutrient additions, to promote plant performance. In this study, basil, Ocimum basilicum (L.), was transplanted into 4 L containers filled with decoupled aquaponic (DAP), nutrient-complemented decoupled aquaponic (DAP+), or chemical-based conventional hydroponic (CON) nutrient solutions and grown for 21 days at $\mathrm{pH} 5.8$. Plants grown in DAP+ and CON had greater biomass, height, and Soil Plant Analysis Development (SPAD) chlorophyll index and lower root:shoot biomass ratios than those in DAP. Shoot fresh and dry biomass was $11 \%$ greater for CON than DAP+, while height, SPAD chlorophyll index, and root:shoot ratio did not differ. We concluded that added nutrients in DAP+ enhanced performance compared to DAP, and the biologically derived nutrition in DAP+ enhanced performance to be similar, but not equal, to CON. We cannot recommend specific adjustments to the targeted blend of complementary nutrients tested, but findings suggest that complementary nutrients are effective in decoupled aquaponics.
\end{abstract}

Keywords: aquaponics; hydroponics; aquaculture; decoupled systems; mineralization; Ocimum basilicum; complementary nutrition; supplemental nutrients

\section{Introduction}

Aquaponics integrates recirculating aquaculture (raising fish) and hydroponics (growing plants without soil). Nutrients from recirculating aquaculture are recycled as fertilizer for the plants, and the plants, in turn, clean the water through uptake of nutrients [1]. Aquaponics systems can produce two food crops with less water, chemical fertilizer, and environmental nutrient runoff than other common food animal and plant production systems [2]. Land-based recirculating aquaculture systems (RAS) and hydroponics can each reduce water use by $90 \%$ or more compared to some conventional aquaculture or field-based agriculture systems [3,4]. Deriving plant nutrition aquaponically can reduce the reliance on chemical fertilizers such as nitrate, potassium and phosphorus, which are usually mined or created with fossil fuel-intensive processes [5]. Synthetic fertilizer production and application contributed to $8 \%$ of global greenhouse gas emissions from agriculture in 2018 [6]. Finally, managing waste from conventional aquaculture is costly and, if mismanaged, can cause negative environmental impacts such as eutrophication in natural ecosystems [7]. Aquaponics can repurpose aquaculture waste as a more environmentally sustainable alternative to some chemical fertilizers. 
Most aquaponics systems are currently coupled, such that water continuously cycles between fish and plant crops. Crop performance in coupled aquaponics can match or exceed conventional hydroponics, in which all nutrients are chemically derived [8]. However, performance in coupled aquaponics sometimes falls short of conventional hydroponics, depending on the fish-plant combination and type of aquaponics system used in the experiment [8]. Fish and nitrifying bacteria tend to require a higher $\mathrm{pH}$ than is optimal for most plant crops [1]. Some essential nutrients are commonly deficient in coupled aquaponics, for example, phosphorus, calcium, iron, manganese and boron [1,9]. Water temperature and pest management strategies may also be limited by conditions required for healthy fish and bacteria on the aquaculture side [4].

In response to the drawbacks of coupled aquaponics, decoupled aquaponics separates the plants and fish systems. This permits adjustments to the water that can benefit the plants without harming the fish [10]. Most decoupled aquaponics systems capture solid fish effluent and wastewater normally lost during filter backwash (cleaning) cycles and mineralizes these waste products into a nutrient solution for plants. The mineralization process can involve aerobic and/or anaerobic microbial digestion of collected aquaculture waste to make nutrients more readily available for plant uptake [2]. Decoupled aquaponic solutions can be adjusted to an optimal $\mathrm{pH}$ for the plants, and supplemental nutrients may be added [2]. Adding supplemental chemical fertilizer to a decoupled aquaponic solution has been shown to substantially increase plant performance [2,8].

Previous research does not quantify the amount or composition of supplementary nutrient additions needed in decoupled aquaponics. Delaide et al., (2016) supplemented a decoupled aquaponic solution such that nutrient concentrations matched those in conventional hydroponics [11]. However, measuring nutrient concentrations in a decoupled aquaponic solution and adding supplemental nutrients to exactly match target values can be impractical for growers and can potentially require large amounts of chemical fertilizer. The target values for conventional hydroponics are not necessarily optimal either and may be in excess. Developing a standardized blend of complementary nutrients that could simply be added to a decoupled aquaponic solution would be more practical for some growers. Evaluating how plant performance is enhanced by this standardized blend of complementary nutrients could help set a baseline reference for further refinement of the amount and composition of complementary chemical fertilizer required.

Basil is a crop that is underexplored in decoupled aquaponics. Basil commands a growing global market as a healthy, high-value crop for growers [12]. It is a common crop in coupled aquaponics and can serve as a model for other specialty herbs such as mint and thyme [13]. Basil performance in coupled aquaponics can equal conventional hydroponics, but not always $[8,14,15]$. There are mixed conclusions surrounding basil performance in decoupled aquaponics. Knaus et al., (2020) found that performance in uncomplemented aquaponics already matched conventional hydroponic levels [16]. Roosta (2014) only found similar performance when the decoupled aquaponic solution was complemented with more than one-third of the chemical fertilizer used in conventional hydroponics [17]. More experiments on basil performance in decoupled aquaponics are needed to draw accurate conclusions.

This study aimed to evaluate the effect of complementary nutrients on basil performance in decoupled aquaponics compared to conventional hydroponics. Our first hypothesis was that plants grown in a complemented decoupled aquaponic solution (DAP+) would outperform those grown in an unsupplemented decoupled aquaponic solution (DAP). This hypothesis is supported by Gillespie et al., (2020), who found that higher concentrations of nutrients in solution directly impacts crop performance [18].

Our second hypothesis was that plants grown in DAP+ would have equal performance to conventional hydroponics $(\mathrm{CON})$, where all nutrients are chemically derived and at sufficient concentrations according to target values for commercial production [19]. Nutrient concentrations in DAP+ would not be at these conventional hydroponic target values; however, the nutrition would be primarily biologically derived. Biologically derived 
nutrition in aquaponic solutions may be part of the reason why aquaponics can match or outperform conventional hydroponics in other studies [8,20]. The chemical fertilizer additions in DAP+ would complement the aquaponic, biologically derived nutrition, not supersede it.

\section{Materials and Methods}

To ensure that nutrient concentrations in DAP+ were primarily biologically derived and that the amount of supplemental chemical fertilizer was substantially less than in conventional hydroponics, we chose to complement the decoupled aquaponic solution with $25 \%$ of the chemical fertilizer used in conventional hydroponics by mass. This reduction in chemical fertilizer could also reduce costs for growers. More details about the formulation of the targeted blend of complementary nutrients is provided in Section 2.5. Genovese basil, Ocimum basilicum (L.), was chosen as the crop of study.

\subsection{Experimental Design}

Three identical experimental trials were conducted between June and August 2021 in the Kenneth Post Lab Greenhouses of Cornell University (Ithaca, NY, USA). Trial 1 started on 8 June and ended on 29 June. Trial 2 started on 30 June and ended on 21 July. Trial 3 started on 22 July and ended on 12 August. For each trial, 36 individual basil plants were grown in $4 \mathrm{~L}$ food-grade plastic buckets (representing mini deep water culture systems) containing treatment solutions and harvested 21 days after transplant. Three treatment solutions were a conventional hydroponic solution (CON) as a control, a decoupled aquaponic solution (DAP), and a complemented decoupled aquaponic solution $(\mathrm{DAP}+)$. Twelve plants were used per treatment in each of the three trials for a total $\mathrm{n}=36$ plants per treatment for the whole experiment.

\subsection{Greenhouse Description}

Experiments were conducted in a section of glass greenhouse range with dimensions 7 $\times 10 \times 7 \mathrm{~m}$ to the ridge, which was oriented east-west. An Argus Titan (Surrey, BC, Canada) monitoring and climate control system regulated air temperature and daily light integral (DLI) with heaters, evaporative cooling, and supplemental lighting. Mean temperature was $23.3^{\circ} \mathrm{C}\left(+/-0.7^{\circ} \mathrm{C} \mathrm{SD}\right)$ for the duration of the experiment, and mean DLI was $24.7 \mathrm{~mol} / \mathrm{day}$ $(+/-2.8 \mathrm{~mol} /$ day SD).

\subsection{Growing System}

In the $0.9 \times 3.6 \mathrm{~m}$ experimental area, 36 buckets, each with a 4 L capacity, were arranged equidistantly ( $30.5 \mathrm{~cm}$ on center) in 3 rows of 12 buckets each. Each bucket was aerated with a $2 \times 4 \mathrm{~cm}$ airstone attached to a central air pump, and bubbling intensity was equal for all buckets by visual observation. Bubbling intensity was not vigorous but disturbed the surface of the solution. All outer bucket surface areas were covered in aluminum foil to prevent algae growth. Every 3 to 4 days within the 21-day growth period, the $\mathrm{pH}$ of the solution in each bucket was adjusted to 5.8 with a Bluelab (Tauranga, New Zealand) METCOM Combo meter, calibrated weekly. As needed, the $\mathrm{pH}$ was lowered using $0.73 \mathrm{M}$ phosphoric acid or raised using $0.72 \mathrm{M}$ potassium carbonate with a volumetric pipette. During these adjustments, more treatment solution was poured into the buckets if water levels were lower than $1 \mathrm{~cm}$ below the lid. This additional treatment solution came from an initial $50 \mathrm{~L}$ batch of $\mathrm{pH}$-adjusted solution, which was stored at $4{ }^{\circ} \mathrm{C}$ for no more than two weeks, or a $10 \mathrm{~L}$ batch that was mixed toward the end of the trials. Both batches in each trial were sent to labs for analysis immediately following $\mathrm{pH}$ adjustment. Analyses of nutrient concentrations for each solution were performed at Cornell Nutrient Analysis Laboratory for Trial 1 and Dairy One (Ithaca, NY, USA) for Trials 2 and 3. Buckets were filled with newly mixed nutrient solution at the start of each trial.

One basil plant was grown in each bucket. A $2.5 \mathrm{~cm}$ square hole was cut in the top of each lid to insert individual $3 \mathrm{~cm}$ square rockwool cubes. Genovese basil Ocimum basilicum 
(L.) seeds were sown in a 200-cell rockwool tray drenched in Jack's (Allentown, PA, USA) 150 ppm N 21-5-20 all-purpose fertilizer solution. A humidity dome was placed over the tray for 2 days, and the seedlings were misted with fertilizer solution. Once most seeds had germinated, the dome was removed, and the seedlings were watered by placing the perforated seedling tray in a closed bottom tray with $2 \mathrm{~L}$ of fertilized water for $5 \mathrm{~min}$ and then removed and allowed to drain. Occasionally, seedlings were misted if the rockwool was drying out. After 14 days, 36 seedlings of similar health and height $(\mathrm{SD}=0.53 \mathrm{~cm})$ from the available 200 plants were transplanted randomly into the bucket systems filled with treatment solutions and grew for 21 days until harvest. The 21-day period allowed plants to grow to a size that was both commercially marketable and differentiable between treatments at harvest. The rockwool cubes were inserted such that the top rested $1 \mathrm{~cm}$ above the bucket lid.

\subsection{Aquaculture and Mineralization Systems}

The $1500 \mathrm{~L}$ RAS system used in the experiment consisted of a $1.5 \mathrm{~m}$ diameter, $0.5 \mathrm{~m}$ deep High-Density Polyethylene (HDPE) tank containing 25 seven-year-old koi fish, 2 settling tanks, a sump with a $115 \mathrm{~V}, 1$ phase, $249 \mathrm{~W}$ submerged utility pump rated at 113/57 Lpm, an AST (Baton Rouge, LA, USA) XS-8000 bubble-bead biofilter, a UV filter, and a splash bar to close the loop. A blackout cloth canopy shielded the fish tank from sunlight and Styrofoam covered the settling tanks. Tap water was supplied as needed through an activated carbon filter to remove chlorine. Koi, a subspecies of carp, Cyprinus carpio (L.), were used in this experiment because they are a long living, stress tolerant species that are used in other commercial aquaponics systems.

Koi were fed $4 \mathrm{~mm}$ floating pellets (Blackwater Creek Farms (Eustis, FL, USA), Max Growth Diet ( $38 \%$ protein, $8 \%$ fat)). Feed was used within 6 months of the mill date. Fish were fed $100 \mathrm{~g}$ and the system $\mathrm{pH}$ was adjusted to 7.0 using potassium carbonate daily. EC measurements were taken using an Oakton (Vernon Hills, IL, USA) "ECTestr 11", pin style conductivity meter that was calibrated to $1413 \mu \mathrm{S} / \mathrm{cm}$ and validated with DI water and a reference thermometer. Solids were manually removed from settling tanks with a syphon weekly. The bead filter was backwashed (flow reversed to remove solids) once every two weeks.

Siphoned wastewater and removed solid waste was transferred to a mineralization tank made from a 210 L HDPE blue barrel ( $59 \mathrm{~cm}$ diameter $\times 88 \mathrm{~cm}$ depth). A $38 \mathrm{~mm}$ diameter spigot was installed $40 \mathrm{~cm}$ from the bottom of the mineralization tank. A $4 \times 4 \times 20 \mathrm{~cm}$ airstone resting on the bottom inside to provided vigorous aeration and mixing. The mineralization tank functioned for over 6 months prior to trials to ensure stability in microbial activity. To collect the decoupled aquaponic solution (DAP) from the mineralization tank, the airstone was turned off for 6 to $12 \mathrm{~h}$ to allow solids to settle, the spigot was opened, and the first 3 to $4 \mathrm{~L}$ of outflow was set aside until the solution ran clear. After clear solution was collected, the initial 3 to $4 \mathrm{~L}$ was returned to the tank, and the airstone was turned on again.

\subsection{Treatment Solutions}

The three treatment solutions included conventional hydroponic control (CON), decoupled aquaponic (DAP), and complemented decoupled aquaponic (DAP+). CON solution was made from calcium nitrate and Jack's (Allentown, PA) 5-12-26 as described by Mattson and Peters (2014) [19]. Then, $37.5 \mathrm{~g}$ of each chemical fertilizer was dissolved separately in $25 \mathrm{~L}$ of water, which were combined to create $50 \mathrm{~L}$ of solution and were all adjusted to a $\mathrm{pH}$ 5.8. The guaranteed analysis for Jack's 5-12-26 is $5 \%$ nitrate- $\mathrm{N}, 12 \%$ available phosphate $\left(\mathrm{P}_{2} \mathrm{O}_{5}\right), 26 \%$ soluble potash $\left(\mathrm{K}_{2} \mathrm{O}\right), 6.32 \%$ water soluble magnesium, $8.21 \%$ combined sulfur, $0.05 \%$ boron, $0.05 \%$ manganese, $0.30 \%$ chelated iron, $0.015 \%$ chelated copper, $0.01 \%$ molybdenum, and $0.015 \%$ chelated zinc. The DAP solution was made by $\mathrm{pH}$ adjusting the clear decoupled aquaponic solution collected as described in Section 2.4. DAP+ solution was made by mixing the targeted blend of chemical fertilizers (Table 1) into $50 \mathrm{~L}$ 
of DAP solution and then $\mathrm{pH}$ adjusting. The amount of chemical fertilizer added was $25 \%$ of the mass of chemical fertilizer in the CON solution. Formulating of the blend of complementary chemical fertilizers considered nutrient concentrations in DAP compared to CON and common nutrient deficiencies in basil (Table 2). Most nutrients were identified as deficient in DAP; thus, macronutrients were prioritized, and micronutrients iron, boron and manganese were selected because they are commonly deficient in basil [21]. First, micronutrients in the form of chelated iron, boric acid, and manganese sulfate were added to the blend to reach $\mathrm{CON}$ concentrations because they required relatively low mass to do so. Next, calcium nitrate and magnesium sulfate were added in proportions that would complement the existing nutrients in DAP to approach CON levels but did not reach them as too much mass would be required. Phosphorus and potassium were not added because $\mathrm{pH}$ adjustments used either phosphoric acid or potassium carbonate for all solutions. The concentrations of specific nutrients added with the blend of complementary nutrients is shown in Table 2 along with target values [19].

Table 1. Targeted blend of complementary nutrients added to the decoupled aquaponic solution.

\begin{tabular}{|c|c|}
\hline Chemical & Grams $50 \mathrm{~L}^{-1}$ \\
\hline Calcium Nitrate $\left(\mathrm{Ca}\left(\mathrm{NO}_{3}\right)_{2}\right)$ & 10 \\
\hline Magnesium Sulfate $\left(\mathrm{MgSO}_{4} \cdot 7 \mathrm{H}_{2} \mathrm{O}\right)$ & 7 \\
\hline Sprint 330 (10\% DTPA Fe) & 1.5 \\
\hline Boric Acid $\left(\mathrm{H}_{3} \mathrm{BO}_{3}\right)$ & 0.15 \\
\hline Manganese Sulfate $\left(\mathrm{MnSO}_{4} \cdot \mathrm{H}_{2} \mathrm{O}\right)$ & 0.1 \\
\hline Total & 18.75 \\
\hline
\end{tabular}

Table 2. Target concentrations (conventional hydroponic, CON), concentrations in DAP solution, concentrations added with the blend of complementary nutrients, and calculated DAP+ concentrations in ppm. Target values in CON according to Mattson and Peters (2014) [19].

\begin{tabular}{ccccccccccccc}
\hline Concentrations & $\mathbf{N}$ & $\mathbf{P}$ & $\mathbf{K}$ & $\mathbf{C a}$ & $\mathbf{M g}$ & $\mathbf{S}$ & $\mathbf{F e}$ & $\mathbf{M n}$ & $\mathbf{Z n}$ & $\mathbf{B}$ & $\mathbf{C u}$ & $\mathbf{M o}$ \\
\hline Target (CON) & 150 & 39 & 162 & 139 & 47 & 64 & 2.3 & 0.38 & 0.11 & 0.38 & 0.11 & 0.075 \\
DAP $^{1}$ & 81.3 & 29.1 & 178.9 & 49 & 17.9 & 28.7 & 0 & 0 & 0.02 & 0.09 & 0.01 & 0 \\
Complementary $^{2}$ & 31 & 0 & 0 & 38 & 14.4 & 19.1 & 3 & 0.65 & 0 & 0.53 & 0 & 0 \\
Calculated DAP+ $^{2}$ & 112.3 & na $^{3}$ & na & 87 & 32.3 & 57.8 & 3 & 0.65 & 0.02 & 0.62 & 0.01 & 0 \\
\hline
\end{tabular}

${ }^{1}$ The system was operating at steady state for two months prior to the start of the experiment. ${ }^{2} \mathrm{DAP}+$ values are the sum of concentrations in DAP and in the complementary blend. ${ }^{3}$ Phosphorus and potassium were added dynamically with $\mathrm{pH}$ adjustments.

Nutrient concentrations were not equal across treatment solutions. There was also variability in nutrient concentrations for DAP because of the dynamic nature of the aquaponics system. However, DAP+ always had the same increase in nutrition compared to DAP such that we could test our first hypothesis that complementary nutrition would enhance performance. Additionally, having lower concentrations of some nutrients in DAP+ compared to $\mathrm{CON}$ ensured nutrients were primarily biologically derived such that we could test our second hypothesis that biologically derived nutrition would enhance basil performance despite having lower nutrient concentrations in solution.

\subsection{Performance Parameters}

Height over time was collected every 3-4 days from the start of the trial. Height over time was measured from the bucket lid to the apical meristem and the added height from the $1 \mathrm{~cm}$ of rockwool was subtracted. On the 21st day after transplant, Soil Plant Analysis Development (SPAD) chlorophyll index was measured with a Konica Minolta (Tokyo, Japan) SPAD-502 $\mathrm{m}$ at harvest by sampling 5 random leaves from oldest to youngest on each plant. The index was used to compare treatments and not to make any assertions of exact chlorophyll content. Then, shoots and roots were clipped directly above and below the rockwool cube and roots were squeezed by hand to remove excess water before weighing. 
Height was taken from the clipped shoot base to the apical meristem for final height. After fresh weight was measured, shoots and roots were dried in paper bags at $50{ }^{\circ} \mathrm{C}$ for 4 days and weighed again. Using the root and shoot dry biomass values, root:shoot biomass ratios were calculated for each plant. Two or three mature leaves were then collected from each plant and pooled for each treatment group to be ground and sent to a lab for analysis. Nutrient analysis of leaf tissue was performed by the Cornell Nutrient Analysis Lab using hot plate digestion plus ICP-AES metals analysis and $\mathrm{C} / \mathrm{N}$ combustion analysis.

\subsection{Statistical Analysis}

The treatments were arranged in a "repeated Latin square" to account for potential gradients in greenhouse conditions. The four Latin squares in each trial consisted of 3 blocks of 3 treatments arranged linearly. All performance variables measured at harvest were analyzed using linear mixed effect models with a fixed effect of treatment and random effects of trial and block nested in trial. Height over time was analyzed using a linear mixed effects model with fixed effects treatment, days after transplant, and the interaction between these variables and random effects of trial and plant ID with the lmerTest package [22]. Days after transplant are $+/-1$ day depending on trial. Fixed effects were tested using F tests with Satterthwaite's method [22]. Pairwise comparisons between treatments were made using Tukey HSD tests. To determine differences in nutrient concentrations in solution and leaf tissue, ANOVA followed by a post-hoc Tukey HSD test was performed. The model assumptions of normality and homogeneous variance were assessed by visual inspection of the residuals. All analyses were performed in R version 3.4.4 and Rstudio [23].

\section{Results}

\subsection{Shoot Fresh and Dry Biomass}

The treatment solution affected mean shoot fresh biomass (Figure 1a). Mean shoot fresh biomass for CON was 11\% greater than for DAP+. Mean shoot fresh biomass for DAP+ was 36\% greater than for DAP (Figure 1a). The effect of treatment solution on mean dry shoot biomass was also significant (Figure 1b). The mean shoot dry biomass for CON was $11 \%$ greater than for DAP+, and the shoot dry biomass for DAP+ was $53 \%$ greater than for DAP (Figure 1b).

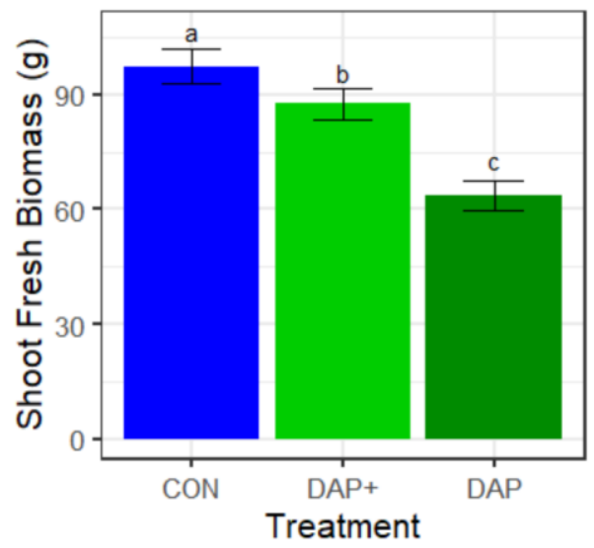

(a)

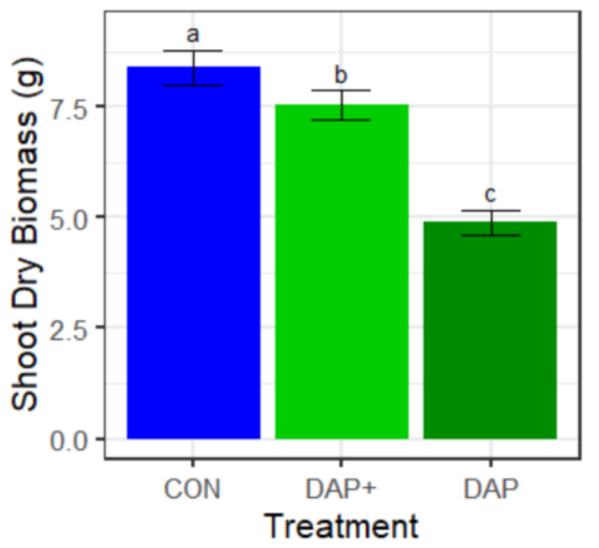

(b)

Figure 1. Effect of different nutrient solutions on (a) basil shoot fresh and (b) dry biomass (mean $+/-$ SE) 21 days after transplant. Treatments are conventional hydroponic (CON), complemented decoupled aquaponic (DAP+), and decoupled aquaponic (DAP) nutrient solutions. Letters denote differences between treatments $(p<0.05)$. 


\subsection{Height, SPAD Chlorophyll Index, and Root:Shoot Biomass Ratio}

The final shoot height of the basil differed across treatment solutions (Figure 2a). The mean height for $\mathrm{CON}$ and DAP+ were similar and were both greater than DAP. The overall effect of treatment solution on mean SPAD chlorophyll index was significant $(p<0.05$, Figure $2 b$ ). The mean chlorophyll index for $\mathrm{CON}$ was not different than $\mathrm{DAP}+$, and the mean index for both CON and DAP+ was greater than DAP. The effect of treatment solution on mean dry root:shoot biomass ratio was also significant (Figure 2c). The mean ratio for $\mathrm{CON}$ was not different than DAP+ and the mean ratio for both CON and DAP+ was lower than DAP.

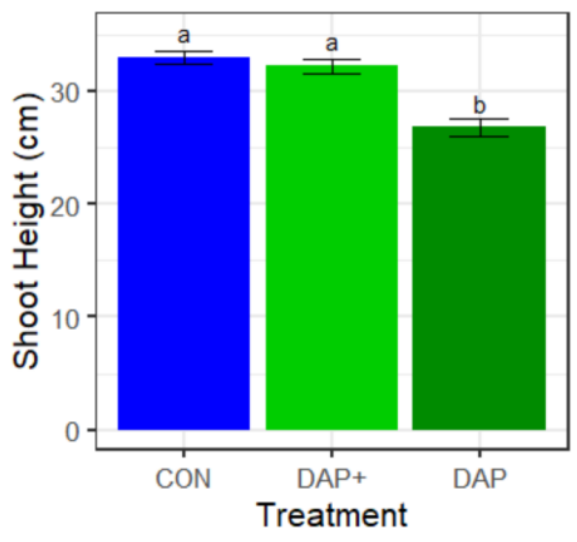

(a)

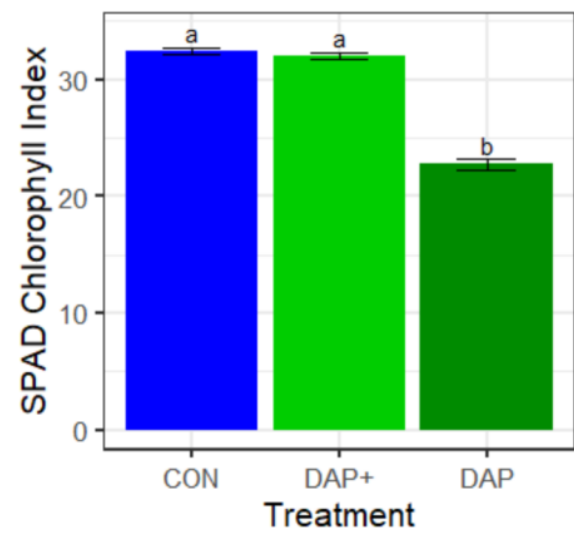

(b)

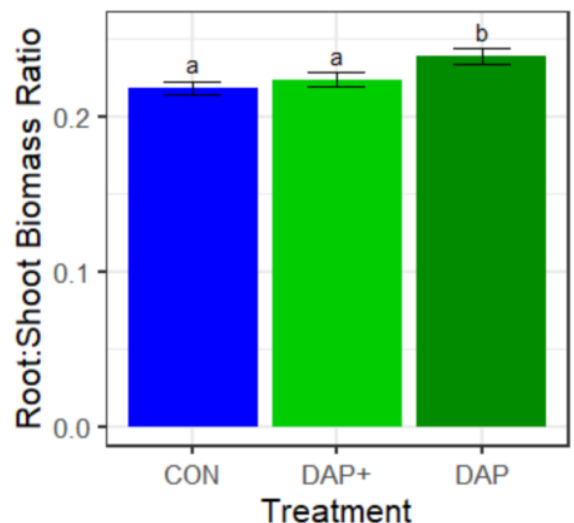

(c)

Figure 2. Effect of different nutrient solutions on (a) basil shoot height and (b) basil leaf Soil Plant Analysis Development (SPAD) chlorophyll index, and (c) root:shoot biomass ratio (means +/ - SE) 21 days after transplant. Treatments are conventional hydroponic $(\mathrm{CON})$, complemented decoupled aquaponic (DAP+), and decoupled aquaponic (DAP) nutrient solutions. Letters denote differences between treatments $(p<0.05)$.

\subsection{Height over Time}

There was an effect of treatment solution $(p<0.05)$, days after transplant (time) $(p<0.05)$ and their interaction $(p<0.05$, Figure 3$)$ on shoot height. The mean heights for $\mathrm{CON}$ and DAP+ remained similar throughout the trials, while height for DAP lagged behind both beginning on day 11 until harvest (Figure 3).

\subsection{Treatment Nutrient Solution Analysis}

Nutrient concentrations in solution differed across treatments for select nutrients (Table 3). Three total outliers were removed if $1.5 \mathrm{IQR}$ (inter-quartile range) was less than the first quartile or greater than the third quartile. Concentrations differed for nitratenitrogen, phosphorus, calcium, magnesium, sulfate-S, iron, manganese, zinc, boron, copper, and molybdenum (Table 3). The nitrogen, calcium, magnesium, sulfur, and manganese concentrations were highest in $\mathrm{CON}$, followed by DAP+, and then DAP. Iron concentrations were highest in $\mathrm{DAP}+$, followed by $\mathrm{CON}$, and then DAP. Phosphorus, zinc, copper, and molybdenum concentrations were highest in $\mathrm{CON}$ and equal in DAP+ and DAP. Phosphorus concentrations were affected by $\mathrm{pH}$ adjustments using phosphoric acid. In general, more acid was used in $\mathrm{CON}$ than DAP+ or DAP to lower $\mathrm{pH}$. Potassium concentrations were equal across all solutions. For boron, an analysis was only able to be performed once, but suggests a trend similar to that of iron with DAP+ having the highest concentration, followed by CON and then DAP. 


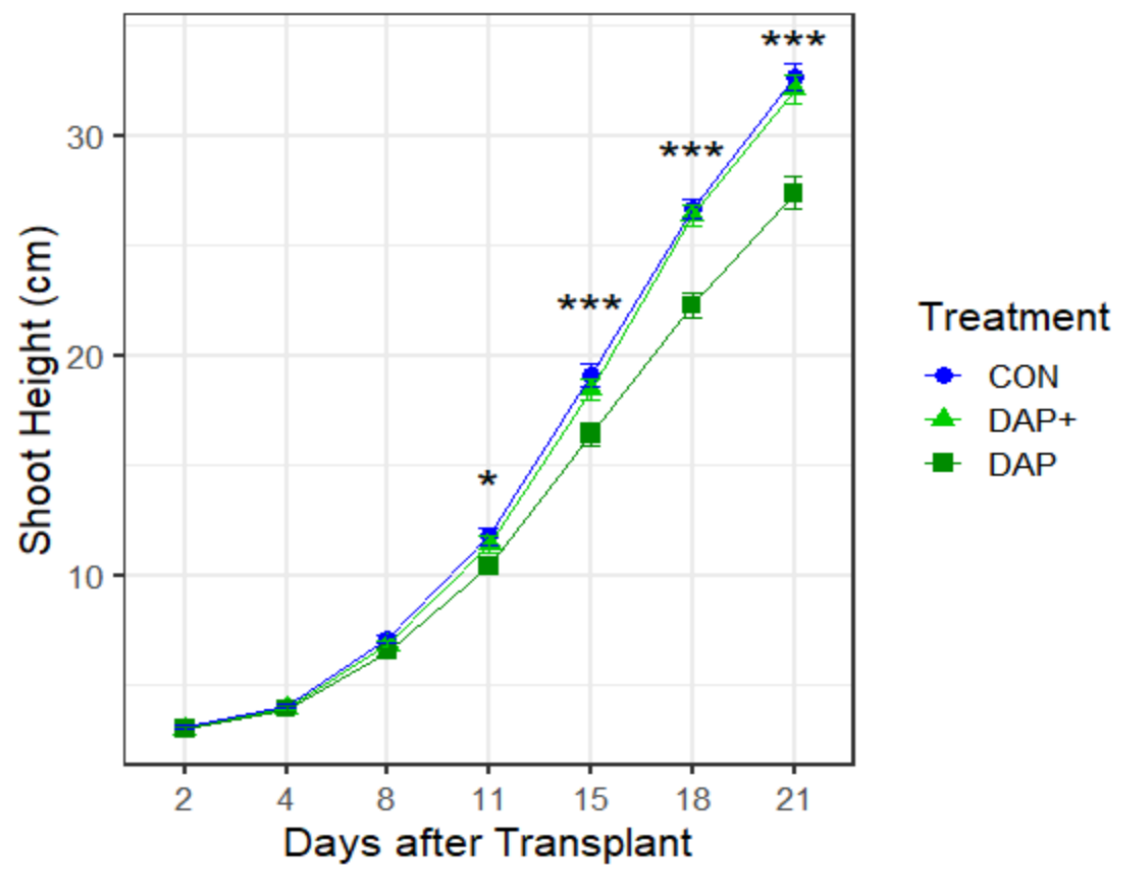

Figure 3. Basil shoot height to apical meristem for different treatment solutions conventional hydroponic (CON) in blue, complemented decoupled aquaponic (DAP+) in light green, and decoupled aquaponic (DAP) in dark green over 21 days. Days after transplant are $+/-1$ day depending on trial. Asterisks denote height for CON and DAP+ differ from DAP: ${ }^{*}(p<0.05),{ }^{* * *}(p<0.001)$.

Table 3. Mean nutrient concentrations in treatment solutions and (standard error). All values are ppm.

\begin{tabular}{|c|c|c|c|c|c|c|c|c|c|c|c|c|}
\hline Trtmt ${ }^{1}$ & $\mathrm{~N}^{2}$ & $\mathbf{P}$ & $\mathbf{K}$ & $\mathrm{Ca}$ & Mg & $S$ & $\mathrm{Fe}$ & Mn & $\mathrm{Zn}$ & B & $\mathrm{Cu}$ & Mo \\
\hline Target $^{3}$ & 150 & 39 & 162 & 139 & 47 & 64 & 2.3 & 0.38 & 0.11 & 0.38 & 0.11 & 0.075 \\
\hline $\mathrm{CON}$ & $\begin{array}{c}138.6^{\mathrm{a}} \\
(4.05)\end{array}$ & $\begin{array}{c}90.4^{\mathrm{a}} \\
(3.6)\end{array}$ & $\begin{array}{c}177.1 \\
(10.1)\end{array}$ & $\begin{array}{c}176.1^{\mathrm{a}} \\
(3.0)\end{array}$ & $\begin{array}{c}47.0^{\mathrm{a}} \\
(0.7)\end{array}$ & $\begin{array}{c}91.8^{\mathrm{a}} \\
(4.5)\end{array}$ & $\begin{array}{l}2.40^{a} \\
(0.17)\end{array}$ & $\begin{array}{l}0.42^{a} \\
(0.02)\end{array}$ & $\begin{array}{l}0.22^{\mathrm{a}} \\
(0.01)\end{array}$ & $\begin{array}{l}0.43 \\
\text { (na) }\end{array}$ & $\begin{array}{l}0.20^{a} \\
(0.02)\end{array}$ & $\begin{array}{c}0.07^{\mathrm{a}} \\
(0)\end{array}$ \\
\hline $\mathrm{DAP}+$ & $\begin{array}{c}102.6^{\mathrm{b}} \\
(6.95)\end{array}$ & $\begin{array}{c}26.8^{b} \\
(2.9)\end{array}$ & $\begin{array}{l}179.4 \\
(20.7)\end{array}$ & $\begin{array}{c}81.8^{\mathrm{b}} \\
(2.1)\end{array}$ & $\begin{array}{c}20.2^{b} \\
(0.9)\end{array}$ & $\begin{array}{c}52.3^{b} \\
(3.1)\end{array}$ & $\begin{array}{l}3.37^{b} \\
(0.25)\end{array}$ & $\begin{array}{l}0.73^{b} \\
(0.11)\end{array}$ & $\begin{array}{c}0.03^{\mathrm{b}} \\
(0)\end{array}$ & $\begin{array}{l}0.63 \\
\text { (na) }\end{array}$ & $\begin{array}{c}0.01^{\mathrm{b}} \\
(0)\end{array}$ & $\begin{array}{l}0^{b} \\
(0)\end{array}$ \\
\hline DAP & $\begin{array}{c}81.3^{c} \\
(5.1)\end{array}$ & $\begin{array}{c}29.1^{b} \\
(2.9)\end{array}$ & $\begin{array}{l}178.9 \\
(19.6)\end{array}$ & $\begin{array}{l}49^{\mathrm{c}} \\
(2.1)\end{array}$ & $\begin{array}{c}17.9^{\mathrm{c}} \\
(0.7)\end{array}$ & $\begin{array}{c}28.7^{\mathrm{c}} \\
(2.1)\end{array}$ & $\begin{array}{l}0^{\mathrm{c}} \\
(0)\end{array}$ & $\begin{array}{l}0^{\mathrm{c}} \\
(0)\end{array}$ & $\begin{array}{c}0.02^{\mathrm{b}} \\
(0)\end{array}$ & $\begin{array}{l}0.09 \\
\text { (na) }\end{array}$ & $\begin{array}{c}0.01^{b} \\
(0)\end{array}$ & $\begin{array}{l}0^{\mathrm{b}} \\
(0)\end{array}$ \\
\hline$(\mathrm{N})^{4}$ & 4 & 5 & 5 & 4 & 4 & 5 & 5 & 5 & 5 & 1 & 5 & 5 \\
\hline
\end{tabular}

${ }^{1}$ Treatment nutrient solutions are conventional hydroponic (CON), complemented decoupled aquaponic (DAP+), and decoupled aquaponic (DAP). ${ }^{2}$ Within columns, means followed by different letters denote differences between treatments $(p<0.05) .{ }^{3}$ Target concentrations according to Mattson and Peters [19]. ${ }^{4}$ Number of observations (N).

\subsection{Leaf Tissue Nutrient Analysis}

In leaf tissue, nutrient concentrations differed for magnesium, manganese, and boron (Figure 4). Concentrations of magnesium and boron were lower in DAP+ than DAP, and $\mathrm{CON}$ did not differ from either. Concentrations of manganese did not differ between DAP+ and CON but were lower in DAP. Differences between treatments for other nutrients were not significant. Across treatments, concentrations of nitrogen, magnesium, sulfur, iron, zinc, and boron were at or below sufficient levels and potassium was above [24]. 

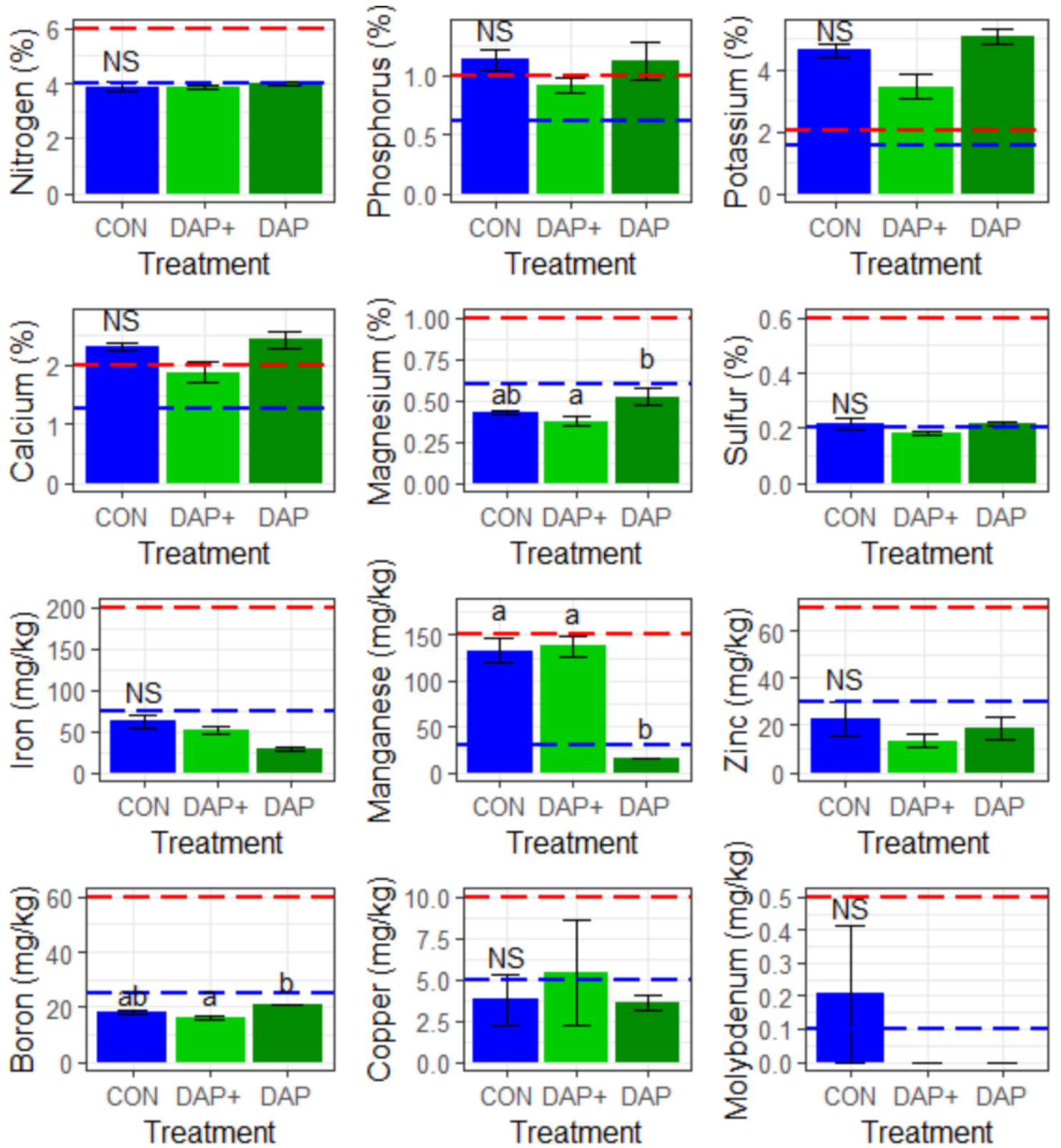

Figure 4. Nutrient concentrations for mature basil leaves grown in each treatment (mean $+/-1 \mathrm{SE}$ ). Treatments are conventional hydroponic $(\mathrm{CON})$, complemented decoupled aquaponic (DAP+), and decoupled aquaponic (DAP) nutrient solutions. Letters denote differences between treatments $(p<0.05)$; NS, no significance. Leaf tissue nutrient sufficiency ranges recommended for basil are indicated by blue (minimum) and red (maximum) dotted lines [24].

\subsection{Visual Observation}

Basil leaves for DAP, and DAP+ to a lesser degree, had interveinal chlorosis, which could indicate magnesium or iron deficiencies (Figure 5). Some new leaves for plants in all treatments were deformed, which could indicate magnesium or boron deficiencies [21]. 


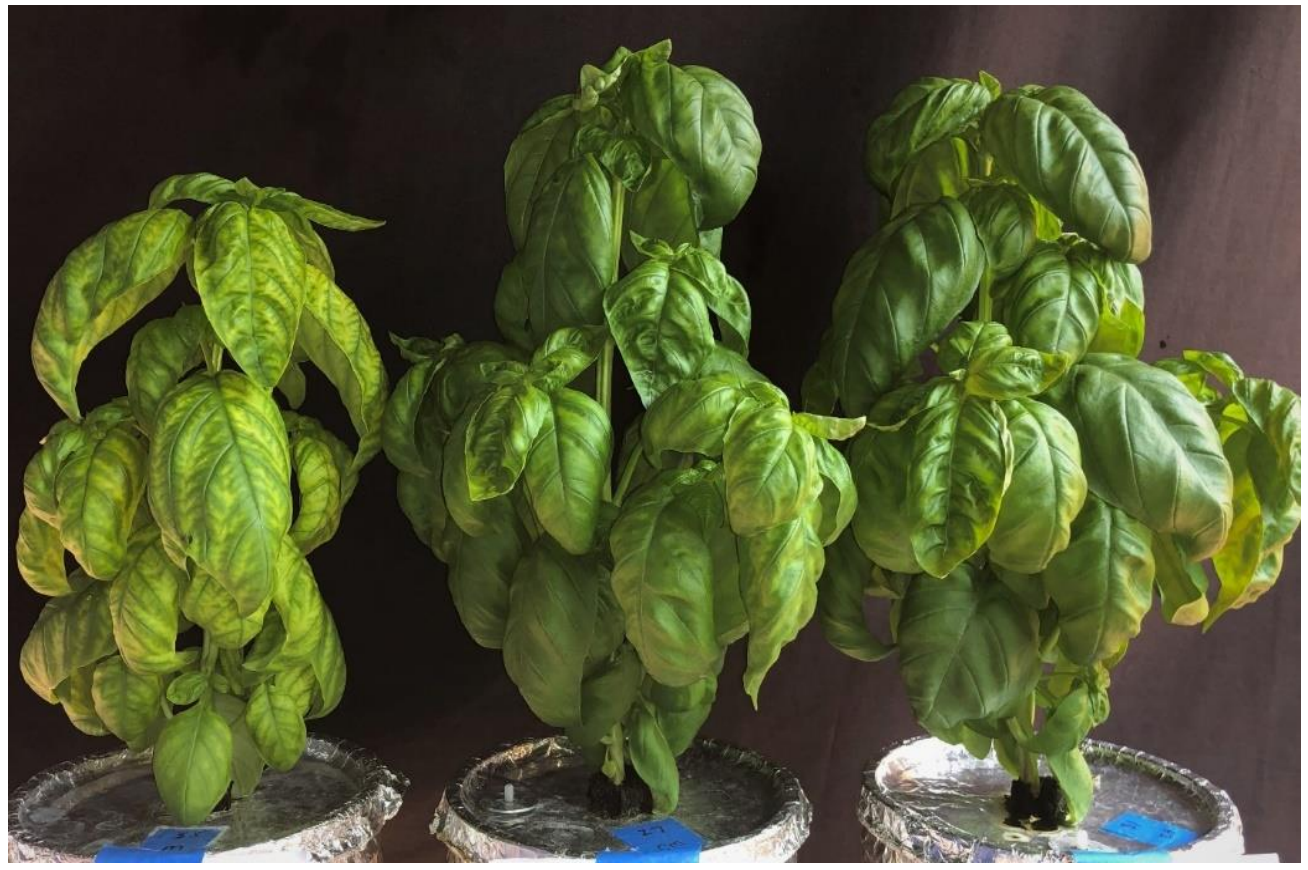

Figure 5. Photograph of a representative sample of the plants grown in different treatments 21 days after transplant. From left to right: DAP, DAP+, and CON.

\section{Discussion}

\subsection{Analysis}

Plants grown in a complemented decoupled aquaponic solution (DAP+) outperformed those grown in a decoupled aquaponic solution (DAP). Adding a targeted blend of complementary nutrients to a decoupled aquaponic solution increased performance compared to the unsupplemented decoupled aquaponic solution for all parameters measured: shoot fresh and dry biomass (Figure 1), shoot height, SPAD chlorophyll index, root:shoot biomass ratio (Figure 2), and height over time (Figure 3). The enhanced performance of basil grown in DAP+ was likely attributed to the higher concentrations of nutrients in DAP+ compared to DAP. For the complementary nutrients added, the DAP+ solution had higher nutrient concentrations than the DAP solution (Table 3). These results supported the first hypothesis that $\mathrm{DAP}+$ would outperform DAP because of higher nutrient concentrations in solution.

Plants grown in the DAP+ solution had similar, but not equal, performance compared to those grown in the conventional hydroponic solution (CON). CON plants had $11 \%$ greater shoot fresh and dry biomass than the DAP+ plants (Figure 1). Shoot height, SPAD chlorophyll index, root:shoot biomass ratio (Figure 2), and height over time (Figure 3) for DAP+ and CON plants did not differ. While most production parameters were similar between $\mathrm{CON}$ and $\mathrm{DAP}+$, the $\mathrm{CON}$ solution would nevertheless have resulted in $11 \%$ more revenue if selling fresh basil shoots by weight.

Comparing DAP+ and $\mathrm{CON}$, nutrient concentrations alone could not explain the similar performance because the concentrations in $\mathrm{DAP}+$, for most essential nutrients were lower than in CON (Table 3). However, the nutrition in DAP+ was primarily biologically derived from the mineralized fish effluent, whereas nutrition in CON was all chemically derived. Performance in DAP+ was likely enhanced by this biologically derived nutrition. Few studies have explored the reason why biologically derived plant nutrition enhances performance in aquaponics. Studies suggest the microbial activity in aquaponic solutions could have enhanced performance [20], but plants in sterilized aquaponic solutions have been shown to outperform those in unsterilized solutions [25]. More research on the mechanisms behind this performance enhancement in aquaponics is needed. These results partially supported the second hypothesis that DAP+ performance would equal CON because of biologically derived nutrition. 
Evaluating crop performance in aquaponics systems is context specific. Nutrient concentrations in decoupled aquaponic solutions can differ because of feed type and rate, stocking density, and fish species. The crop grown can also affect performance, as some crops are better or worse suited for aquaponics systems. The performance parameters measured for those crops also influences conclusions. Conclusions in this study should be considered in terms of the Koi-rearing system described in Materials and Methods Section 2 and the performance parameters for the specific crop, basil.

We evaluated basil performance based on a variety of measured parameters. Shoot fresh and dry biomass are important indicators of plant performance and vigor. Shoot fresh biomass is an important variable for growers selling this part of the plant. Height is also an indicator of plant performance, but it is less important for most growers. The SPAD chlorophyll index is correlated with chlorophyll content in basil leaves, which determines the photosynthetic performance of a plant [26]. It also relates to lushness of green for leaves, which can be important for growers. A greater root:shoot biomass ratio indicates that a plant is allocating more resources to root growth than shoot growth, which may be caused by nutrient stress [27]. This can limit overall performance [28]. Overall, better performance was indicated by greater shoot fresh and dry biomass, taller plants, higher SPAD chlorophyll indices, and lower root:shoot biomass ratios.

\subsection{Previous Research}

The results support previous research demonstrating that basil in complemented aquaponics outperformed a non-complemented counterpart and performed similarly, but not equal, to conventional hydroponics when a third of the amount of hydroponic fertilizer was used to fertilize plants [17]. Roosta (2014) adjusted the number of times 4 L drip-todrain hydroponics systems were irrigated with aquaponic and hydroponic solution whereas this study used $4 \mathrm{~L}$ deep water culture hydroponic systems filled with complemented decoupled aquaponic solution [17]. Our results differ from Knaus et al., (2020), who found that performance in uncomplemented aquaponics already matched conventional hydroponic levels [16]. It is hard to directly compare results in aquaponics because systems are unique and dynamic. The aquaponics system that Knaus et al., (2020) used in the experiment appeared to have a greater stocking density of a different fish species than used in this experiment [16].

Conclusions can be affected by other factors as well. Performance in the chosen conventional hydroponic system can vary based on the nutrient solution and hydroponics system used $[17,29]$. Performance also varies by crop and associated performance parameter measured. Pickens (2015) found that tomato and cucumber performance in uncomplemented decoupled aquaponics was less than in conventional hydroponics, whereas Delaide et al., (2016) found that lettuce outperformed conventional hydroponics [12,29]. The results in this study are consistent with previous research, but more studies are still needed to draw accurate conclusions [8].

\subsection{Adjustments to the Complemented Blend}

The broader applied goal for this study was to quantify the amount and composition of a standardized targeted blend of nutrients that growers could add to a decoupled aquaponic solution. The blend used in the study enhanced the performance of DAP+ compared to DAP but was not enough to match that of CON. This could indicate that not enough complementary chemical fertilizer was added to the decoupled aquaponic solution. As for the composition of the blend, we planned to determine which nutrients in DAP+ were still deficient using (1) nutrient concentrations in solution (Table 3), (2) nutrient concentrations in leaf tissue (Figure 4), and (3) visual observations (Figure 5). However, this analysis was inconclusive, as there were contradictions between the three factors analyzed.

Contradictions between nutrients concentrations in leaf tissue and solution were apparent and inconsistent with visual observations. Leaf tissue nutrient concentrations can be used to evaluate deficiencies [30,31]. In leaf tissue, nutrient concentrations in DAP+ did not 
differ or were less than DAP, but in solution, concentrations in DAP+ did not differ or were greater than DAP (Table 3, Figure 4). There were also more observed nutrient deficiency symptoms in DAP than DAP+ (Figure 5) [21]. For example, in leaf tissue, magnesium concentrations were lower in DAP+ than DAP, despite having higher concentrations in solution. However, concentrations in DAP+ were higher than DAP by less than the calculated amount (Tables 2 and 3). Perhaps another form of magnesium besides magnesium sulfate should be used in the complementary blend. More severe magnesium deficiency symptoms were observed in DAP than DAP+ (Figure 5). Magnesium deficiency is especially common in basil; thus, this nutrient in particular would require deeper analysis [32]. However, new leaf deformations observed in all treatments could indicate magnesium and boron deficiency, which was supported by sub-sufficient levels of those nutrients in leaf tissue (Figures 4 and 5) [24]. Additionally, manganese concentrations in both leaf tissue and solution were greater in DAP+ than DAP. This indicates that complementing some target nutrients can reduce nutrient deficiencies in decoupled aquaponics. More research exploring these contradictions and the mechanisms of nutrient uptake in decoupled aquaponics is needed.

In general, we recommend increasing the amount of complementary chemical fertilizer by a small margin but cannot make specific recommendations in terms of composition of the targeted blend itself without further research. Concentrations of nitrogen, magnesium, sulfur, iron, zinc, and boron were all at the lower range of sufficient levels in leaf tissue and could be complemented more if the amount of added chemical fertilizer is increased (Figure 4). This blend was tested in the context of the crop, performance parameters, and aquaculture system used. Other aquaponics systems may require more or less complementary nutrients, or a different composition of nutrients, for the targeted blend. If the amount of complementary chemical fertilizer is increased, implications for environmental sustainability should be considered.

\section{Conclusions}

Overall, the targeted blend of complementary nutrients tested substantially enhanced basil performance in decoupled aquaponics to reach levels similar, but not equal, to conventional hydroponics. Growers, both aquaculturists and agriculturists alike, could use this technology to grow plants with aquaculture waste and to support environmental, and potentially economic sustainability. There are opportunities to further optimize complementary nutrition and mineralization in decoupled aquaponics for a variety of fish-plant combinations. Research surrounding the mechanisms involved in these complex systems would also provide valuable insights for optimization. While there is much more to discover, our results indicate that complementary nutrients are effective in decoupled aquaponics.

Author Contributions: Conceptualization, D.R.; methodology, D.R.; validation, D.R., E.W., N.M. and M.B.T.; formal analysis, D.R., E.W., N.M. and M.B.T.; resources, D.R., E.W., N.M. and M.B.T.; data curation, D.R.; writing — original draft preparation, D.R.; writing-review and editing, D.R., E.W., N.M. and M.B.T.; visualization, D.R.; supervision, E.W., N.M. and M.B.T.; project administration, D.R.; funding acquisition, D.R., E.W., N.M. and M.B.T. All authors have read and agreed to the published version of the manuscript.

Funding: This work was supported by joint research under Project No. 1237650 and extension program funded by the Cornell University Agricultural Experiment Station (Hatch/Multistate funds) and Cornell Cooperative Extension (Smith Lever funds) received from the National Institutes of Food and Agriculture (NIFA), U.S. Department of Agriculture (USDA). Support was also provided by the Northeast Regional Aquaculture Center under Project No. 20183850028885. Any opinions, findings, conclusions, or recommendations expressed in this publication are those of the author(s) and do not necessarily reflect the view of USDA.

Institutional Review Board Statement: Cornell University Institutional Animal Care and Use Committee (IACUC) protocol \#2012-0127 which includes monthly inspection and annual recertification. 
Data Availability Statement: No new data were created or analyzed in this study. Data sharing is not applicable to this article.

Acknowledgments: This experiment would not have been possible without the help of Brooke DelPrete and J. Osborn. Statistics advice and review were given by Cornell Statistics Unit, Katja Poveda and Uriel Menalled. Growing advice and maintenance were provided by the wonderful greenhouse staff at Kenneth Post Laboratories. Thank you to all reviewers.

Conflicts of Interest: The authors declare no conflict of interest.

\section{References}

1. Rakocy, J.E. Aquaponics-Integrating Fish and Plant Culture. In Aquaculture Production Systems; John Wiley \& Sons, Inc.: Ames, IA, USA, 2012.

2. Goddek, S.; Joyce, A.; Kotzen, B.; Burnell, G. Aquaponics Food Production Systems; Springer International Publishing: Cham, Switzerland, 2019; pp. 163-267. ISBN 978-3-030-15943-6.

3. Timmons, M.B. Recirculating Aquaculture, 4th ed.; Ithaca Publishing Company LLC: Ithaca, NY, USA, 2018 ; pp. 663-709.

4. Goddek, S.; Delaide, B.; Mankasingh, U.; Ragnarsdottir, K.V.; Jijakli, H.; Thorarinsdottir, R. Challenges of Sustainable and Commercial Aquaponics. Sustainability 2015, 7, 4199-4224. [CrossRef]

5. Lal, R. Carbon Emission from Farm Operations. Environ. Int. 2004, 30, 981-990. [CrossRef] [PubMed]

6. FAO. Emissions Due to Agriculture. Global, Regional and Country Trends 2000-2018; FAOSTAT Analytical Brief Series No. 18; FAO: Rome, Italy, 2020.

7. Cripps, S.; Bergheim, A. Solids Management and Removal for Intensive Land-Based Aquaculture Production Systems. Aquac. Eng. 2000, 22, 33-59. [CrossRef]

8. Ayipio, E.; Wells, D.; McQuilling, A.; Wilson, A. Comparisons between Aquaponic and Conventional Hydroponic Crop Yields: A Meta-Analysis. Sustainability 2019, 11, 6511. [CrossRef]

9. Suhl, J.; Dannehl, D.; Kloas, W.; Baganz, D.; Jobs, S.; Scheibe, G.; Schmidt, U. Advanced Aquaponics: Evaluation of Intensive Tomato Production in Aquaponics vs. Conventional Hydroponics. Agric. Water Manag. 2016, 178, 335-344. [CrossRef]

10. Sallenave, R.; Shultz, C.R. Decoupled Aquaponics: A Comparison to Single-Loop Aquaponics; New Mexico State University: Las Cruces, NM, USA, 2017.

11. Delaide, B.; Goddek, S.; Gott, J.; Soyeurt, H.; Jijakli, M.H. Lettuce (Lactuca Sativa L. Var. Sucrine) Growth Performance in Complemented Aquaponic Solution Outperforms Hydroponics. Water 2016, 8, 467. [CrossRef]

12. Industry Research. Global Basil Leaves Market Research Report 2021; Industry Research: Los Angelos, CA, USA, 2021.

13. Rakocy, J.; Shultz, R.C.; Bailey, D.S.; Thoman, E.S. Aquaponic Production of Tilapia and Basil: Comparing Batch and Staggered Cropping System. Acta Hortic. 2004, 448, 63-69. [CrossRef]

14. Dunwoody, R.K. Aquaponics and Hydroponics: The Effect of Nutrient Source and Hydroponic Subsystem Design on Sweet Basil Production. Master's Thesis, Masters of Science, University of Central Missouri, Warrensburg, MO, USA, 2013.

15. Saha, S.; Monroe, A.; Day, M.R. Growth, Yield, Plant Quality and Nutrition of Basil (Ocimum Basilicum L.) under Soilless Agricultural Systems. Ann. Agric. Sci. 2016, 61, 181-186. [CrossRef]

16. Knaus, U.; Pribbernow, M.; Xu, L.; Appelaum, S.; Palm, H. Basil (Ocimum Basilicum) Cultivation in Decoupled Aquaponics with Three Hydro-Components (Grow Pipes, Raft, Gravel) and African Catfish (Clarias Gariepinus) Production in Northern Germany. Sustainability 2020, 12, 8745. [CrossRef]

17. Roosta, H.R. Comparison of the Vegetative Growth, Eco-Physiological Characteristics and Mineral Nutrient Content of Basil Plants in Different Irrigation Ratios of Hydroponic:Aquaponic Solutions. J. Plant Nutr. 2014, 37, 1782-1803. [CrossRef]

18. Gillespie, D.; Kubota, C.; Miller, S. Effects of Low pH of Hydroponic Nutrient Solution on Plant Growth, Nutrient Uptake, and Root Rot Disease Incidence of Basil (Ocimum Basilicum L.). HortScience 2020, 55, 8. [CrossRef]

19. Mattson, N.S.; Peters, C. A Recipe for Hydroponic Success. Inside Grower 2014, 2014, 16-19.

20. Khalil, S.; Panda, P.; Ghadamgahi, F.; Rosberg, A.; Vetukuri, R.R. Comparison of Two Commercial Recirculated Aquacultural Systems and Their Microbial Potential in Plant Disease Suppression. BMC Microbiol. 2021, 21, 205. [CrossRef] [PubMed]

21. Mattson, N.; Merrill, T. Nutrient Deficiencies in Hydroponic Basil. e-Gro Res. Update. 2016, 1-10. Available online: http: / / www.e-gro.org/pdf/2016-4.pdf (accessed on 13 December 2021).

22. Kuznetsova, A.; Brockhoff, P.B.; Christensen, R.H.B. LmerTest Package: Tests in Linear Mixed Effects Models. J. Stat. Soft. 2017, 82, 1-26. [CrossRef]

23. R Core Team. R: A Language and Environment for Statistical Computing; R Foundation for Statistical Computing: Vienna, Austria, 2020.

24. Owen, W.G.; Cockson, P.; Henry, J.; Whipker, B.; Currey, C.J. Basil (Ocimum Basilicum). e-Gro Nutr. Monit. 2018, 1, 7.

25. Wielgosz, Z.; Anderson, T.; Timmons, M.B. Microbial Effects on the Production of Aquaponically Grown Lettuce. Horticulturae 2017, 3, 46. [CrossRef]

26. Ruiz-Espinoza, F.H.; Murillo-Amador, B.; García-Hernández, J.L.; Fenech-Larios, L.; Rueda-Puente, E.O.; Troyo-Diéguez, E.; Kaya, C.; Beltrán-Morales, A. Field Evaluation of the Relationship Between Chlorophyll Content in Basil Leaves and A Portable Chlorophyll Meter (SPAD-502) Readings. J. Plant Nutr. 2010, 33, 423-438. [CrossRef] 
27. Lynch, J.; Marschner, P.; Rengel, Z. Chapter 13-Effect of Internal and External Factors on Root Growth and Development. In Marschner's Mineral Nutrition of Higher Plants, 3rd ed.; Marschner, P., Ed.; Academic Press: San Diego, CA, USA, 2012; pp. 331-346. ISBN 978-0-12-384905-2.

28. Kang, J.-G.; van Iersel, M.W. Nutrient Solution Concentration Affects Shoot: Root Ratio, Leaf Area Ratio, and Growth of Subirrigated Salvia (Salvia Splendens). HortScience 2004, 39, 49-54. [CrossRef]

29. Suh, E.; Park, K. Effect of Different Concentrations of Nutrient Solutions on the Growth, Yield, and Quality of Basil. Acta Hortic. 1999, 483, 193-198. [CrossRef]

30. Walters, K.J.; Currey, C.J. Effects of Nutrient Solution Concentration and Daily Light Integral on Growth and Nutrient Concentration of Several Basil Species in Hydroponic Production. HortScience 2018, 53, 1319-1325. [CrossRef]

31. Solis-Toapanta, E.; Fisher, P.; Gómez, C. Growth Rate and Nutrient Uptake of Basil in Small-Scale Hydroponics. HortScience 2020, 55, 507-514. [CrossRef]

32. Mattson, N.S. Magnesium Deficiency of 2018 Sponsors Hydroponic and Container Grown Basil. e-Gro Edible Alert 2018, 3, 6. 